\title{
HÍBRIDOS DE MILHO PIPOCA CULTIVADOS SOB DIFERENTES LÂMINAS DE IRRIGAÇÃO
}

\section{MAIZE POPCORN HYBRIDS CROPPED UNDER IRRIGATION DEPTHS}

\author{
Marizangela Rizzatti ÁVILA ${ }^{1}$ \\ Eder Pereira GOMES ${ }^{1}$ \\ Gregory FEDRI ${ }^{2}$ \\ Carlos Alberto SCAPIM ${ }^{1}$ \\ Davi Antonio Oliveira BARIZÃO ${ }^{2}$ \\ Leandro Paiola ALBRECHT ${ }^{3}$ \\ Marcos Araújo RODOVALHO ${ }^{3}$
}

\begin{abstract}
RESUMO
A pesquisa agronômica do milho pipoca no Brasil ainda é muito incipiente, sobretudo no tocante a manejo da irrigação. Portanto, o objetivo do trabalho foi avaliar as características agronômicas, os componentes de produção, produtividade e capacidade de expansão de diferentes híbridos de milho pipoca, cultivados sob diferentes lâminas de irrigação, embasadas em variações de coeficientes de cultura, na região do arenito caiuá. O ensaio foi instalado no ano agrícola de 2007/2008 na Fazenda do Campus Regional de Umuarama, PR, pertencente à Universidade Estadual de Maringá. O delineamento experimental foi em blocos casualizados com quatro repetições instaladas no campo em esquema de parcelas subdivididas. As parcelas foram compostas por variações do coeficiente de cultura (Kc) seguindo os seguintes valores: 0 (testemunha), 0,8; 1 (referência); 1,2 e 1,4 Kc e as subparcelas pelos híbridos (Jade e IAC 125). As variáveis avaliadas foram: altura de plantas; altura de inserção da primeira espiga; diâmetro de espiga; comprimento de espiga; massa de cem grãos; produtividade e capacidade de expansão. Em relação aos caracteres analisados, o híbrido IAC 125, na presença de irrigação e na variação de Kc acima da referência para a cultura do milho, em geral, é mais responsivo. A prática da irrigação é um manejo válido para o bom desempenho da cultura do milho pipoca.

Palavras-chave: Zea mays; solo arenoso; irrigação; componentes de produção.
\end{abstract}

\section{ABSTRACT}

Maize popcorn in concern to its agronomic research is still incipient, mainly regarding to its irrigation management systems. For this reason, the objective of this study was to assess the agronomic traits, yield components, productivity and expansion capacity of different maize popcorn hybrids, cropped under different crop coefficients (Kc) on Caiuá sandstone region. The experiment was installed in a randomized block design with four replications on the field in a scheme of subdivided parcels at the Regional Campus of Umuarama Experimental Station Farm, Paraná, belonging to the State University of Maringá. The plots were composed by the variations of Kc reference by following values: 0 (without treatment); $0.8 ; 1$ (reference); 1.2 and $1.4 \mathrm{Kc}$ and subplots were hybrids (Jade and IAC 125). Variables assessed were: plant height; first spike insertion height; spike's diameter; spike's length; 100-grain mass; productivity as well as expansion capacity. According to the characters analyzed, hybrid IAC 125, in general, is more responsive regarding irrigation presence and Kc variation mentioned above for that of corn crop reference. Therefore, irrigation practice has been a valid scheme in order to obtain a good performance on maize popcorn.

Key-words: Zea mays, sandstone soil; irrigation; yield components.

\footnotetext{
${ }^{1}$ Professor (a) Adjunto da Universidade Estadual de Maringá, Departamento de Agronomia - Campus Regional de Umuarama, Estrada da Paca s/n. Bairro São Cristóvão, 87507-190, Umuarama, PR. E-mail: marizangela rizzatti@hotmail.com; ederpgomes@gmail.com; cascapim@uem.br ${ }^{2}$ Acadêmico do curso de agronomia, Bolsista de Iniciação Científica (PIBIC). Departamento de Agronomia - Campus Regional de Umuarama, Estrada da Paca s/n. Bairro São Cristóvão, 87507-190, Umuarama, PR. E-mail: agrofedri@yahoo.com; deividy_17@hotmail.com ${ }^{3}$ Acadêmico de Pós graduação em Agronomia da Universidade Estadual de Maringá, Bolsista do CNPq. E-mail: Ipalbrecht@yahoo.com.br; marcos_rodovalho@hotmail.com
} 
ÁVILA, M. R. et al. Híbridos de milho pipoca...

\section{INTRODUÇÃO}

A produção brasileira de milho pipoca é insuficiente para atender o mercado nacional e apresenta-se como um mercado promissor, no entanto, há demanda de muitas pesquisas para esta cultura.

O Paraná, comumente, é tido como o principal produtor de milho do Brasil, possuindo pacotes tecnológicos definidos, pautados em sólida pesquisa, no entanto, o mesmo empenho científico não é nítido para o sistema produtivo do milho pipoca e principalmente em cultivo irrigado.

O milho pipoca é caracterizado por possuir grãos pequenos e duros que têm a capacidade de estourar/expandir quando aquecidos em torno de $180{ }^{\circ} \mathrm{C}$, diferenciando-se, deste modo, do milho comum, embora pertença à mesma espécie botânica, Zea mays L. (Oliveira et al., 2007).

A produção nacional deste produto é de aproximadamente 20 mil toneladas e o consumo está em torno de 80 mil toneladas, sendo $75 \%$, desse mercado, proveniente do milho importado da Argentina e Estados Unidos (Sawazaki, 2001).

Devido à demanda de milho pipoca no Brasil estar sendo atendida por importações, pouco estímulo existe, quanto a obtenção de informações agronômicas sobre o seu cultivo e as informações que se tem não são concretas. Desta forma, informações como, melhor época de semeadura, viabilidade no cultivo em safrinha, zoneamento edafoclimático, manejo de irrigação, híbridos mais adaptados e com bom empalhamento, diâmetro do colmo, altura adequada, resistência a doenças, alta produtividade e também características que agradam o consumidor como: capacidade de expansão, maciez e textura do grão e número de piruás, entre outras, são muito importantes para que se consolide o cultivo de milho pipoca.

No país existem poucos pólos de cultivo de milho pipoca, destacando-se aqueles localizados nas regiões de Itapetininga e Tatuí, em São Paulo, Itumbiara, em Goiás e Barreiras, na Bahia, além do Rio Grande do Sul, bem como aqueles onde se concentram as empresas empacotadoras.

A região noroeste do Estado do Paraná é formada por solo de arenito que se destaca por apresentar baixo potencial de armazenamento de água. Neste local concentra-se elevada quantidade de pequenas propriedades agrícolas ocupada na maioria de sua extensão com pastagens degradadas. Sendo assim, a diversificação das atividades agrícolas nestas pequenas propriedades é uma alternativa para aumentar a renda do produtor, pois permite a inclusão de culturas de maior valor econômico por área. Contudo, devido às características de solo bem como de clima da região, a suplementação com água através de irrigação seria indispensável para alguns cultivos anuais como é o milho pipoca. O que poderia ser bastante interessante sob o ponto de vista econômico uma vez que há empresas empacotadoras na região.

A cultura do milho requer um consumo de 400 a $800 \mathrm{~mm}$ de água em seu ciclo completo para uma boa produtividade. As maiores exigências em água para essa cultura, assim como, para a grande maioria das culturas anuais concentram-se na fase de emergência, florescimento e formação dos grãos, portanto a ocorrência de déficits hídricos nestes períodos são os que provocam maiores reduções de produtividade (Lozada \& Angelocci, 1999; Matzenaurei, 2002; Rezende et al., 2003; Bergamaschi et al., 2004; Cardoso et al., 2004; Fancelli \& Dourado Neto, 2008).

A irrigação para a cultura do milho pode ser viável economicamente quando o fator limitante é a água e/ou o preço de venda do produto é favorável, o que possibilita a minimização de risco e estabilidade no rendimento (Fancelli \& Dourado Neto, 2008), fato que também pode ser observado para a cultura de milho pipoca.

A irrigação consiste no conjunto de técnicas destinadas a deslocar a água no tempo e no espaço, modificando as possibilidades agrícolas de cada região. Logo, o manejo da irrigação é um dos fatores indispensáveis na otimização do uso da água. Contudo, para que o manejo da irrigação se proceda dentro de um critério racional, faz-se necessário ter controle sobre a quantidade de água a ser aplicada sem que esta prejudique a produtividade e o meio ambiente.

Desta forma, o presente trabalho teve como objetivo avaliar as características agronômicas, os componentes de produção, produtividade e capacidade de expansão de grãos de diferentes híbridos de milho pipoca, cultivados sob diferentes lâminas de irrigação.

\section{MATERIAL E MÉTODOS}

O ensaio foi instalado na segunda quinzena de outubro do ano agrícola de 2007/2008 na Fazenda do Campus Regional de Umuarama, PR, pertencente à Universidade Estadual de Maringá. O clima predominante na região é do tipo Cfa, mesotérmico úmido, com chuvas abundantes no verão e inverno seco com verões quentes, segundo classificação de Köppen (IAPAR, 1987). Umuarama está situada a uma latitude de $23^{\circ} 47^{\prime}$ sul e longitude de $53^{\circ} 14^{\prime}$ a oeste de Greenwhich, com altitude de $403 \mathrm{~m}$. O solo do local do experimento é classificado como Latossolo Vermelho Distrófico, típico, com horizonte $A$ apresentando textura franco-arenosa (EMBRAPA, 1999).

Este experimento foi planejado e executado realizando o estudo simultâneo de 2 híbridos de milho pipoca e 5 variações no manejo da irrigação. Para tal adotou-se o delineamento experimental em forma de parcelas subdivididas, com quatro blocos. Compondo o seguinte modelo:

$Y_{i j k}=m+m i_{i}+b_{j}+e_{i j}+h_{k}+m i h_{i k}+e_{i j k}$ em que:

$Y_{\mathrm{ijk}}$ : valor observado na subparcela do i ésimo tratamento primário, $k$ ésimo tratamento secundário no j ésimo bloco;

$\mathrm{m}$ : média geral do experimento;

$\mathrm{mi}_{\mathrm{i}}$ : efeito do tratamento (lâminas de irrigação) i ésimo, $i=1,2,3,4$ e 5 ;

$b_{j}$ : efeito do bloco j ésimo, $j=1,2$, 3.e 4;

$h_{k}$ : efeito do tratamento (híbridos) $k$ ésimo, $k=1$ e 2; 
ÁVILA, M. R. et al. Híbridos de milho pipoca...

$\mathrm{mih}_{\mathrm{ik}}$ : efeito da interação: híbridos x lâminas de irrigação;

$\mathrm{e}_{\mathrm{ij}}$ : erro experimental a nível de parcela;

$e_{i j k}$ : erro experimental a nível de subparcela.

As parcelas foram compostas por diferentes lâminas de irrigação embasadas na variação dos coeficientes de cultura $(\mathrm{Kc})$ : 0 (testemunha, sem irrigação); 0,8 Kc; Kc; 1,2 Kc e 1,4 Kc e, as subparcelas, pelos híbridos (Jade e IAC 125).

Os valores de Kc tomados como referência para a cultura do milho foram pré-fixados de forma decendial, considerando um ciclo de cultivo de 120 dias, com valores de 0,$40 ; 0,50 ; 0,60 ; 0,70 ; 0,90$; 1,$00 ; 1,20 ; 1,20 ; 1,00 ; 0,90 ; 0,80$ e 0,50 , sendo que, no último decêndio a irrigação foi suspensa a fim de realizar a colheita, adotados conforme (Alfonsi et al., 1990, Pereira et al., 2002 e Rezende et al., 2003).

Cada subparcela irrigada continha quatro microaspersores, um em cada extremidade, da marca Naan Dan, modelo Hadar 7110, com bocal cinza e vazão de $0,036 \mathrm{~m}^{3} \mathrm{~h}^{-1}$ à $15 \mathrm{~m}$.c.a de pressão. 0 dimensionamento de cada subparcelas foi de $20 \mathrm{~m}^{2}$ $(4 \times 5 \mathrm{~m})$ e o da parcela foi de $40 \mathrm{~m}^{2}(4 \times 10 \mathrm{~m})$ e a distância entre cada parcela foi de $4 \mathrm{~m}^{2}(2 \times 2 \mathrm{~m})$.

Os híbridos avaliados foram: Jade (híbrido triplo) e IAC 125 (híbrido triplo top cross), híbridos comumente cultivados nas regiões produtoras de milho pipoca, possuindo grande aceitação do público consumidor. A pipoca Jade apresenta grão tipo americano; já o IAC 125 diferencia-se por ser a variedade nacional de pipoca com maior capacidade de expansão de grãos e maior produtividade (Sawazaki, 2005; Oliveira et al., 2007).

O preparo da área experimental iniciou-se com a correção da acidez do solo três meses antes do início do experimento. Após este período fez-se a dessecação da área com glyphosate $(1440 \mathrm{~g}$ de i.a. ha $\left.^{-1}\right)$. Posteriormente adequou-se a fertilidade do solo para a cultura de milho pipoca utilizando-se $500 \mathrm{~kg} \mathrm{ha}^{-1}$ do formulado 8-28-16 (N, $\mathrm{P}_{2} \mathrm{O}_{5}$ e $\left.\mathrm{K}_{2} \mathrm{O}\right)$ para adubação de semeadura. Realizada a adubação fez-se a marcação das parcelas e subparcelas e instalou-se o sistema de irrigação. A adubação de cobertura foi realizada 30 dias após a emergência das plantas utilizando $40 \mathrm{~kg} \mathrm{ha}^{-1}$ de uréia. Os tratos culturais foram realizados conforme as recomendações técnicas para a cultura do milho (Fancelli \& Dourado Neto, 2008; Rezende et al., 2003).

A semeadura foi realizada sobre palhada de braquiária (Brachiaria brizantha), com o auxílio de semeadora manual. As parcelas foram compostas de 4 linhas com espaçamento de $0,90 \mathrm{~m}$ e 0,20 $\mathrm{m}$ entre plantas, totalizando após a emergência uma população de 55.000 plantas por hectare, seguindo as recomendações de Sawazaki (2001).

A primeira irrigação, após a semeadura, foi promovida para que todos os tratamentos iniciassem o ciclo em condições idênticas de umidade no solo. Para tanto, foi determina "in loco" a sua umidade inicial e logo em seguida, com base na curva de retenção de água no solo, aplicou-se uma lâmina suficiente para elevar a umidade do solo à capacidade de campo. O tratamento controle recebeu apenas essa irrigação inicial e posteriormente, apenas água das chuvas.
O manejo da irrigação para os tratamentos irrigados iniciou-se após a emergência das plântulas, estes foram manejados de forma suplementar a partir de leituras obtidas de um tanque Classe $A$. A evaporação do tanque foi relacionada com a velocidade do vento e com a umidade do ar, obtendo-se a ETo (evapotranspiração de referência). Por fim, o produto de ETo por Kc forneceu a evapotranspiração de cultura (ETc) e o produto dos fatores dos tratamentos de irrigação com a ETc resultou na lâmina de água aplicada em cada tratamento, conforme o turno de rega fixo ( 3 vezes por semana). A partir de coletores instalados no centro de cada subparcela, constatou-se que a intensidade de aplicação foi da ordem de $1,44 \mathrm{~mm} \mathrm{~h}^{-1}$, com eficiência de aplicação de $80 \%$.

Os dados meteorológicos referentes a precipitação pluviométrica e balanço hídrico climatológico para o período de condução do experimento encontram-se na Figura 8 . O balanço hídrico climatológico foi realizado a partir dos dados de evapotranspiração de cultura e precipitação, fornecidos pela Estação Agroclimática da Universidade Estadual de Maringá, Campus Regional de Umuarama. Esses dados foram lançados no programa BHNORM versão 5 (Rolim \& Sentelhas, 1999) para elaboração decendial do gráfico de balanço hídrico. Por se tratar de um solo arenoso considerou-se o armazenamento de água igual a $100 \mathrm{~mm} \mathrm{~m}^{-1}$. Considerando o sistema radicular da cultura do milho igual a 0,4 m, obteve-se um CAD (capacidade de água disponível) de $40 \mathrm{~mm}$. Esse valor de CAD foi também utilizado para alimentar o programa BHNORM versão 5 .

Em uma área útil de $7,20 \mathrm{~m}^{2}$, ou seja, nas 2 linhas centrais e em $4 \mathrm{~m}$ lineares de cada subparcela, antes da colheita, avaliaram-se as características agronômicas: altura de plantas, determinada medindo-se 10 plantas aleatoriamente da base até a inserção do pendão e altura da inserção da primeira espiga, realizada nas mesmas 10 plantas escolhidas para determinar a altura das plantas. A altura da inserção da primeira espiga foi determinada medindo-se as plantas da base à altura de inserção da espiga.

Iniciou-se a colheita da área útil de cada subparcela quando os grãos apresentavam $18 \%$ de umidade. Após a colheita realizou-se a despalha das espigas, as quais foram avaliadas quanto aos componentes de produção.

O diâmetro de espiga foi determinado medindo-se 10 espigas escolhidas aleatoriamente após a colheita com o auxilio de um paquímetro.

O comprimento das espigas foi realizado nas mesmas 10 espigas escolhidas para determinar o diâmetro de espiga.

A massa de cem grãos foi determinada por meio da pesagem de oito subamostras de $100 \mathrm{se}$ mentes após a debulha das espigas colhidas na área útil de cada subparcela.

A produtividade foi obtida pelo peso total de grãos debulhados das espigas produzidas na área útil de cada subparcela, com umidade corrigida para $14 \%$. 
Avaliou-se também a capacidade de expansão de grãos, a qual foi obtida a partir da razão entre o volume de pipoca expandida, medida numa proveta com capacidade de $2.000 \mathrm{~cm}^{3}$ e a massa de $30 \mathrm{~g}$ de grãos, determinada em balança de precisão. Foram avaliadas duas amostras por parcela.

A massa de grãos submetidos ao estouro foi obtida do total de grãos colhidos da parte centrobasal das espigas de cada subparcela. Antes da avaliação da capacidade de expansão de grãos, as amostras de grãos e a amostra piloto de $1,0 \mathrm{~kg}$ que serviu para monitoramento da umidade, foram armazenadas em câmara seca e fria. A avaliação da capacidade de expansão e grãos foi efetuada quando a umidade da amostra piloto atingiu uma faixa ideal de $13 \%$ a $15 \%$. Na obtenção da capacidade de expansão de grãos, foi utilizado um pipocador desenvolvido pela Embrapa - Centro Nacional de Pesquisa e Desenvolvimento de Instrumentação Agropecuária (CNPDIA), baseado no testador oficial da capacidade de expansão de grãos da Cretors $\mathrm{CO}$, contendo resistência elétrica e termostato. A temperatura ideal de funcionamento deste equipamento é de $280{ }^{\circ} \mathrm{C}$, com tempo de dois minutos e quinze segundos das amostras de grãos na panela (Pacheco et. al, 1998)

Após as avaliações de campo e laboratório os dados obtidos para todas as variáveis foram submetidos à análise de variância. O modelo biométrico adotado foi com efeito fixo para híbridos e lâminas de irrigação. Foram calculadas as esperanças do quadrado médio - $E(Q M)$ - conforme modelo biométrico adotado e, segundo pressupostos de Cruz et al. (2004).

A avaliação dos híbridos em cada lâmina de irrigação foi realizada pelo teste $F$, conclusivo $(P<0,05)$. Enquanto a variação do manejo da irrigação para cada híbrido foi analisada por regressão polinomial a fim de verificar o comportamento das características a $5 \%$ de probabilidade. $\mathrm{Na}$ escolha do melhor modelo de regressão foram adotados os seguintes critérios: regressão significativa, desvios da regressão não-significativa, coeficiente de determinação e análise de resíduos.

\section{RESULTADOS E DISCUSSÃO}

As lâminas de irrigação aplicadas por meio dos tratamentos $0,8 \mathrm{Kc}, 1 \mathrm{Kc}, 1,2 \mathrm{Kc}$ e $1,4 \mathrm{Kc}$ foram iguais $217,1,252,8,288,5$ e $324,5 \mathrm{~mm}$, respectivamente.

As variáveis altura de planta, altura de inserção de primeira espiga, diâmetro de espiga, comprimento de espiga e massa de cem grãos não apresentaram diferenças significativas $(P<0,05)$ entre os híbridos de milho pipoca cultivados para cada variação no manejo da irrigação, inclusive na testemunha, sem irrigação, $(0 \mathrm{Kc})$ Tabela 1.

A produtividade entre os híbridos foi maior para o Jade em todas as lâminas de irrigação utilizadas com exceção da lâmina $324,50 \mathrm{~mm}$, em que não houve diferença significativa de produtividade entre os híbridos (Tabela 1). Isto ocorreu provavelmente devido à diferença genética observada entre os híbridos, o que também é relatado na literatura para os diferentes genótipos de milho pipoca estudados quanto a produtividade em diversos ambientes. De uma forma geral, genótipos como IAC 112, Zélia, Ames 4198, UFLA 1 e BRS Angela apresentaram produção acima $2.600 \mathrm{~kg} \mathrm{ha}^{-1}$, em determinadas regiões de Minas Gerais. Galvão et al. (2000) testando materiais híbridos, obtiveram média de produtividade de, $4.604 \mathrm{~kg} \mathrm{ha}^{-1} \mathrm{com}$ valores entre $3.000 \mathrm{~kg} \mathrm{ha}^{-1}$ e $5.500 \mathrm{~kg} \mathrm{ha}^{-1}$. Coimbra (2000), em condições irrigadas, obteve produtividade de 4.924 $\mathrm{kg} \mathrm{ha}^{-1}$ com progênies da população DFT1 de milho pipoca e as médias das testemunhas foram de $5.400 \mathrm{~kg} \mathrm{ha}^{-1}$ (Zélia), $5.311 \mathrm{~kg} \mathrm{ha}^{-1}$ (IAC 112) e $5.100 \mathrm{~kg} \mathrm{ha}^{-1}$ (RS 20), estes valores estão próximos aos conseguidos neste trabalho para o híbrido Jade quando utilizou-se lâminas com valores de Kc iguais a 1 e 1,2 e, para o híbrido IAC $125 \mathrm{com}$ Kc de 1,4.

O híbrido IAC 125 apresentou maior capacidade de expansão que o Jade quando as lâminas de irrigação foram embasadas em 0,8 Kc (40,25 e $\left.36,16 \mathrm{~cm}^{3} \mathrm{~g}^{-1}\right)$; Kc $\left(41,08\right.$ e $\left.36,66 \mathrm{~cm}^{3} \mathrm{~g}^{-1}\right) ; 1,2 \mathrm{Kc}$ $\left(40,00\right.$ e $\left.38,75 \mathrm{~cm}^{3} \mathrm{~g}^{-1}\right)$ e $1,4 \mathrm{Kc}\left(41,08\right.$ e $37,00 \mathrm{~cm}^{3}$ $\mathrm{g}^{-1}$ ) e não diferiu quando a cultura não foi irrigada $\left(34,66\right.$ e $\left.36,58 \mathrm{~cm}^{3} \mathrm{~g}^{-1}\right)$ Tabela 1. A capacidade de expansão é uma característica inversamente proporcional a produtividade, massa de grãos e umidade dos grãos (Sawazaki et al., 1986). Por outro lado, Song \& Eckahoff (1994) relatam que o tamanho do grão e o genótipo também afetam significativamente o volume de expansão e o número de grãos estourados. Os resultados relatados tanto por Sawazaki et al. (1986) e por Song \& Eckahoff (1994) estão de acordo com este trabalho para produtividade dos tratamentos que foram irrigados e em relação a comparação dos diferentes híbridos.

Para Galvão et al. (2000) o índice de capacidade de expansão entre 21 e 26 são considerados bons e acima de 26 são excelentes. A capacidade de expansão para os dois híbridos testados neste trabalho independente da lâmina utilizada se enquadra como excelente e também se enquadra dentro da escala utilizada pelas empacotadoras no Estado do Paraná que trabalham com um índice mínimo de 30 , considerando o volume de pipoca $\left(\mathrm{cm}^{3}\right)$ dividido pelo peso da amostra $(\mathrm{g})$.

$\mathrm{Na}$ Figura 1 observa-se que para o híbrido IAC 125, a altura de planta respondeu de maneira linear à irrigação, no entanto, no caso do híbrido Jade, houve uma resposta quadrática, onde a maior altura de planta $(167,4 \mathrm{~cm})$ equivale a uma lâmina de $280 \mathrm{~mm}$. Este valor é superior a lâmina de irrigação que seria obtida por meio da utilização dos valores de Kc de referência, igual a $252,8 \mathrm{~mm}$. No caso da IAC 125 a menor altura, sem irrigação, foi de $141,6 \mathrm{~cm}$. A irrigação promoveu a partir daí um acréscimo de $0,094 \mathrm{~cm}$ por $\mathrm{mm}$ de água aplicado. Plantas de milho pipoca muito altas não são desejáveis devido a possibilidade das plantas acamarem e ou quebrarem. 
ÁVILA, M. R. et al. Híbridos de milho pipoca...

Tabela 1. Características agronômicas, componentes de produção, produtividade e capacidade de expansão para dois híbridos de milho pipoca cultivados em diferentes manejos de irrigação. Umuarama, PR. Safra 2007/2008.

\begin{tabular}{|c|c|c|c|c|c|}
\hline \multirow[t]{2}{*}{ Híbridos $^{1}$} & \multicolumn{5}{|c|}{ Lâmina de irrigação (mm) } \\
\hline & $\mathbf{0}$ & 217,10 & 252,80 & 288,50 & 324,50 \\
\hline & \multicolumn{5}{|c|}{ Altura de planta (cm) } \\
\hline IAC 125 & $141,57 \mathrm{~A}$ & $165,50 \mathrm{~A}$ & $158,00 \mathrm{~A}$ & $153,25 \mathrm{~A}$ & $185,00 \mathrm{~A}$ \\
\hline JADE & $138,50 \mathrm{~A}$ & $162,25 \mathrm{~A}$ & $166,50 \mathrm{~A}$ & $181,25 \mathrm{~A}$ & $160,25 \mathrm{~A}$ \\
\hline Média & 140,04 & 163,88 & 162,25 & 167,25 & 172,63 \\
\hline \multirow[t]{2}{*}{ C.V. (\%) } & 4,24 & & & & \\
\hline & \multicolumn{5}{|c|}{ Altura de inserção da primeira espiga (cm) } \\
\hline IAC 125 & $85,95 \mathrm{~A}$ & $92,50 \mathrm{~A}$ & $89,50 \mathrm{~A}$ & $87,10 \mathrm{~A}$ & $88,75 \mathrm{~A}$ \\
\hline JADE & $80,75 \mathrm{~A}$ & $88,50 \mathrm{~A}$ & $83,50 \mathrm{~A}$ & $86,50 \mathrm{~A}$ & $89,75 \mathrm{~A}$ \\
\hline Média & 83,35 & 90,50 & 86,50 & 86,80 & 89,25 \\
\hline C.V. (\%) & 1,94 & & & & \\
\hline \multicolumn{6}{|c|}{ Diâmetro da espiga (cm) } \\
\hline IAC 125 & $2,84 \mathrm{~A}$ & $3,22 \mathrm{~A}$ & $3,18 \mathrm{~A}$ & $3,11 \mathrm{~A}$ & $3,31 \mathrm{~A}$ \\
\hline JADE & $2,91 \mathrm{~A}$ & $3,21 \mathrm{~A}$ & $3,08 \mathrm{~A}$ & $3,22 \mathrm{~A}$ & $3,19 \mathrm{~A}$ \\
\hline Média & 2,87 & 3,21 & 3,13 & 3,16 & 3,25 \\
\hline C.V. (\%) & 2,78 & & & & \\
\hline \multicolumn{6}{|c|}{ Comprimento da espiga $(\mathrm{cm})$} \\
\hline IAC 125 & $12,32 \mathrm{~A}$ & $14,67 \mathrm{~A}$ & $15,01 \mathrm{~A}$ & $14,30 \mathrm{~A}$ & $15,67 \mathrm{~A}$ \\
\hline JADE & $14,02 \mathrm{~A}$ & $15,70 \mathrm{~A}$ & $14,91 \mathrm{~A}$ & $15,24 \mathrm{~A}$ & $15,08 \mathrm{~A}$ \\
\hline Média & 13,17 & 15,18 & 14,96 & 14,77 & 15,37 \\
\hline C.V. (\%) & 4,40 & & & & \\
\hline \multicolumn{6}{|c|}{ Massa de cem sementes $(\mathrm{g})$} \\
\hline IAC 125 & $15,57 \mathrm{~A}$ & $14,79 \mathrm{~A}$ & $15,06 \mathrm{~A}$ & $14,42 \mathrm{~A}$ & $15,43 \mathrm{~A}$ \\
\hline JADE & $13,23 \mathrm{~A}$ & $14,84 \mathrm{~A}$ & $14,49 \mathrm{~A}$ & $15,42 \mathrm{~A}$ & $15,04 \mathrm{~A}$ \\
\hline Média & 14,40 & 14,81 & 14,77 & 14,92 & 15,23 \\
\hline C.V. (\%) & 6,39 & & & & \\
\hline \multicolumn{6}{|c|}{ Produtividade (kg ha $\left.{ }^{-1}\right)$} \\
\hline IAC 125 & $1.118,91 \mathrm{~B}$ & $2.315,61 \mathrm{~B}$ & $2.769,43 \mathrm{~B}$ & $3.484,88 \mathrm{~B}$ & $5.208,37 \mathrm{~A}$ \\
\hline JADE & $3.099,08 \mathrm{~A}$ & $3.735,06 \mathrm{~A}$ & $5.495,57 \mathrm{~A}$ & $5.783,60 \mathrm{~A}$ & $4.488,76 \mathrm{~A}$ \\
\hline Média & $2.108,99$ & $3.025,34$ & $4.132,50$ & $4.634,24$ & $4.848,56$ \\
\hline C.V. (\%) & 6,31 & & & & \\
\hline \multicolumn{6}{|c|}{ Capacidade de expansão $\left(\mathrm{mL} \mathrm{g}^{-1}\right)$} \\
\hline IAC 125 & $34,66 \mathrm{~A}$ & $40,25 \mathrm{~A}$ & $41,08 \mathrm{~A}$ & $40,00 \mathrm{~A}$ & $41,08 \mathrm{~A}$ \\
\hline JADE & $36,58 \mathrm{~A}$ & $36,16 \mathrm{~B}$ & $36,66 \mathrm{~B}$ & $38,75 \mathrm{~B}$ & $37,00 \mathrm{~B}$ \\
\hline Média & 35,62 & 38,21 & 38,87 & 39,38 & 39,04 \\
\hline C.V. (\%) & 4,28 & & & & \\
\hline
\end{tabular}

${ }^{1}$ Médias seguidas de mesma letra maiúscula, em cada coluna, para a mesma variável, não diferem entre si pelo teste $\mathrm{F}$, a $5 \%$ de probabilidade. 
ÁVILA, M. R. et al. Híbridos de milho pipoca...

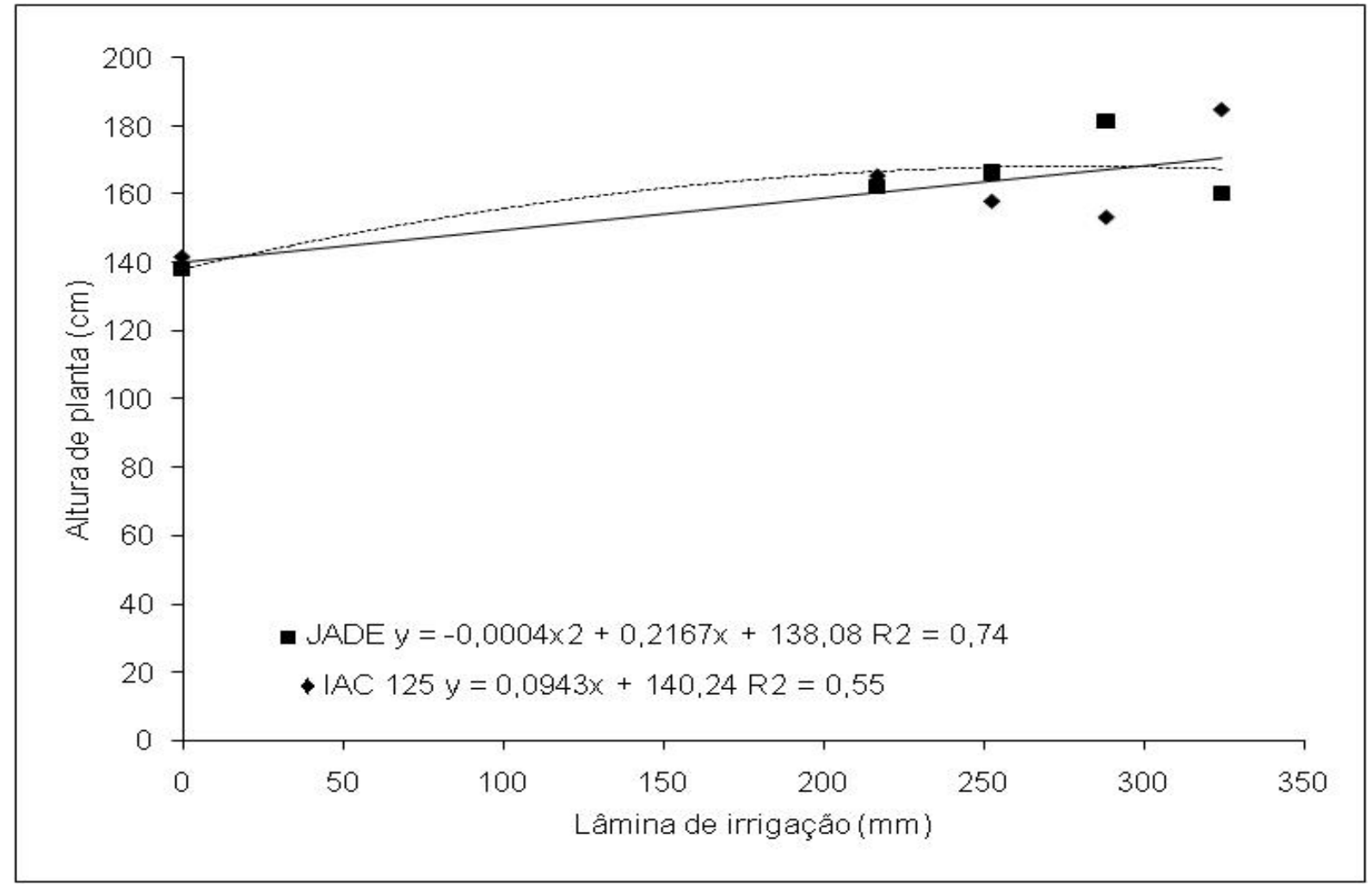

FIGURA 1 - Comportamento da altura de planta para cada híbrido de milho pipoca em função da lâmina de irrigação. Umuarama, PR. Safra 2007/2008.

No caso da altura de inserção da primeira espiga (Figura 2), o comportamento, em função da irrigação, foi quadrático para o IAC 125 e linear para o Jade, com acréscimo de $0,023 \mathrm{~cm}$ por $\mathrm{mm}$ de lâmina de água. Para o IAC 125 a maior altura de inserção da primeira espiga equivale $(92,7 \mathrm{~cm})$ a uma lâmina de $160 \mathrm{~mm}(92,8 \mathrm{~mm}$ abaixo da lâmina de referência).

Geralmente os genótipos que apresentam maior altura de plantas também apresentam maior inserção da espiga, porém estes resultados foram inversos neste trabalho conforme pode ser observado nas Figuras 1 e 2.

Para diâmetro de espiga (Figura 3), verificou-se comportamento linear para o híbrido IAC 125 , com acréscimo de $0,0013 \mathrm{~cm}$ por $\mathrm{mm}$ de água. No caso do Jade, observa-se comportamento quadrático assintótico, com maior valor de diâmetro de espiga observado na lâmina $288,5 \mathrm{~mm}$ $(1,2 \mathrm{Kc})$.

$\mathrm{Na}$ Figura 4, observa-se para o híbrido Jade, resposta quadrática com maior comprimento de espiga $(15,42 \mathrm{~cm})$ referente a uma lâmina de irrigação de $220 \mathrm{~mm}$ (32,8 mm inferior a lâmina de referência). Para o genótipo IAC 125, ajuste linear descreve um incremento de $0,0093 \mathrm{~cm}$ por $\mathrm{mm}$ de lâmina de água, portanto quanto há suplementação com água as espigas são maiores.

Características como comprimento e diâmetro da espiga de milho pipoca podem ser importantes para o desempenho das máquinas degranadoras. No caso de milho doce há preferência por espigas maiores devido à maior eficiência das máquinas para corte de acordo com Paiva Júnior (1999).

A massa de cem grãos, do híbrido IAC 125 , não respondeu de maneira significativa $(P<0,05)$ à lâmina de irrigação. No caso do híbrido Jade, houve resposta quadrática, obtendo-se 0 maior valor de massa de cem grãos $(18,74 \mathrm{~g})$ quando utilizou-se uma lâmina de irrigação igual a $230 \mathrm{~mm}$ (22,8 mm inferior a lâmina de referência), Figura 5. 
ÁVILA, M. R. et al. Híbridos de milho pipoca...

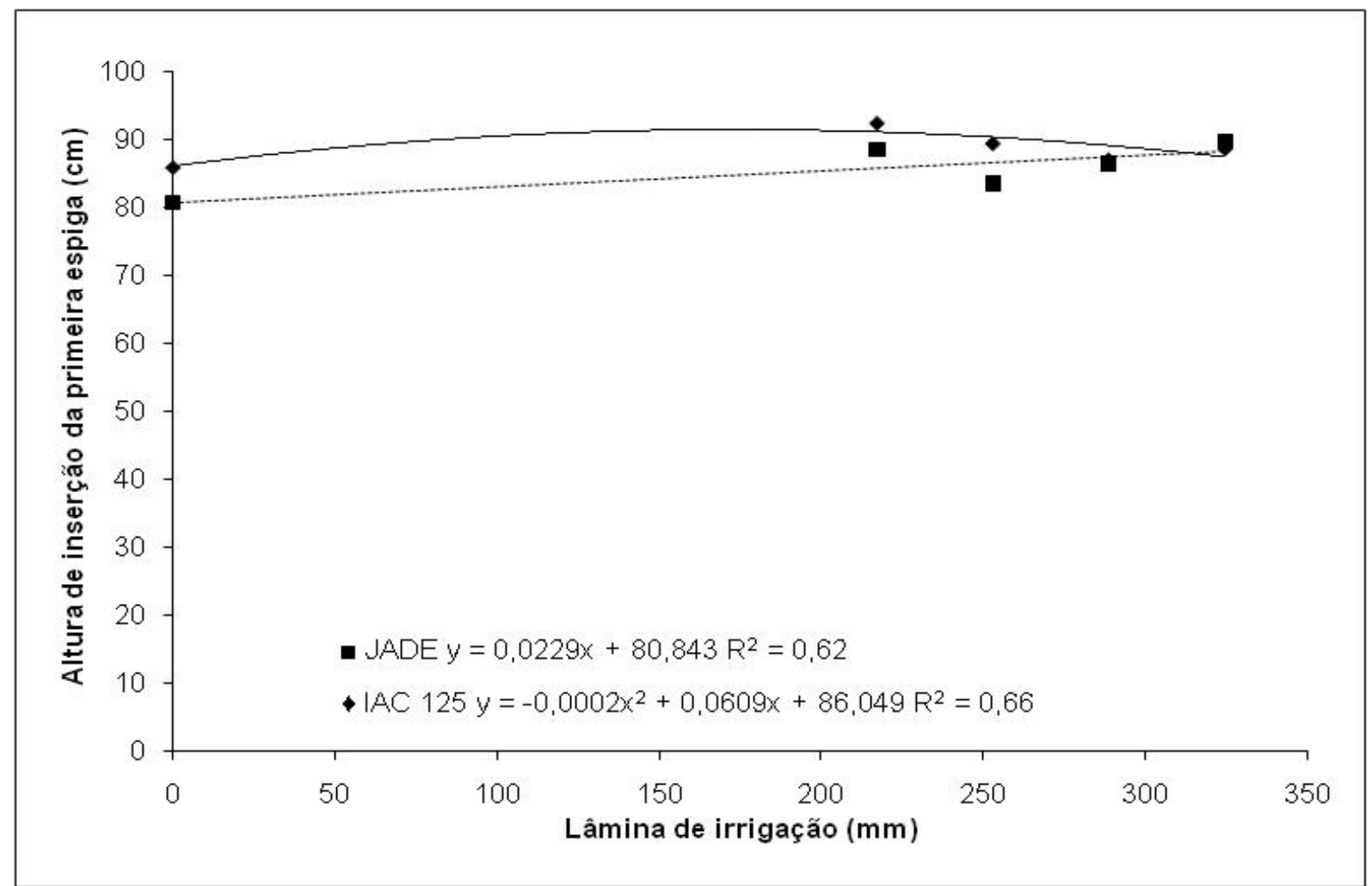

FIGURA 2 - Comportamento da altura de inserção da primeira espiga para cada híbrido de milho pipoca em função da lâmina de irrigação. Umuarama, PR. Safra 2007/2008.

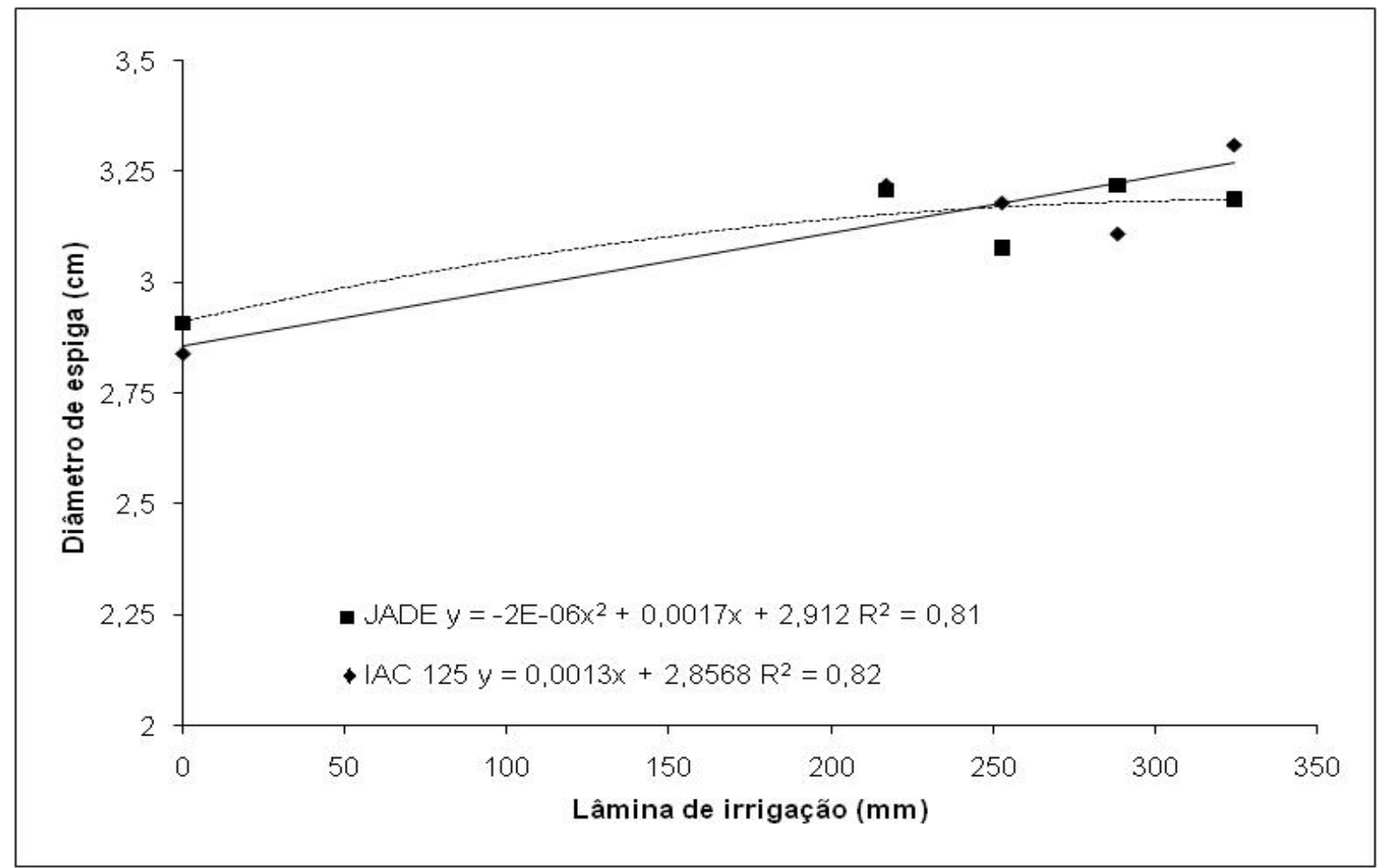

FIGURA 3 - Comportamento do diâmetro de espiga para cada híbrido de milho pipoca em função da lâmina de irrigação. Umuarama, PR. Safra 2007/2008. 
ÁVILA, M. R. et al. Híbridos de milho pipoca...

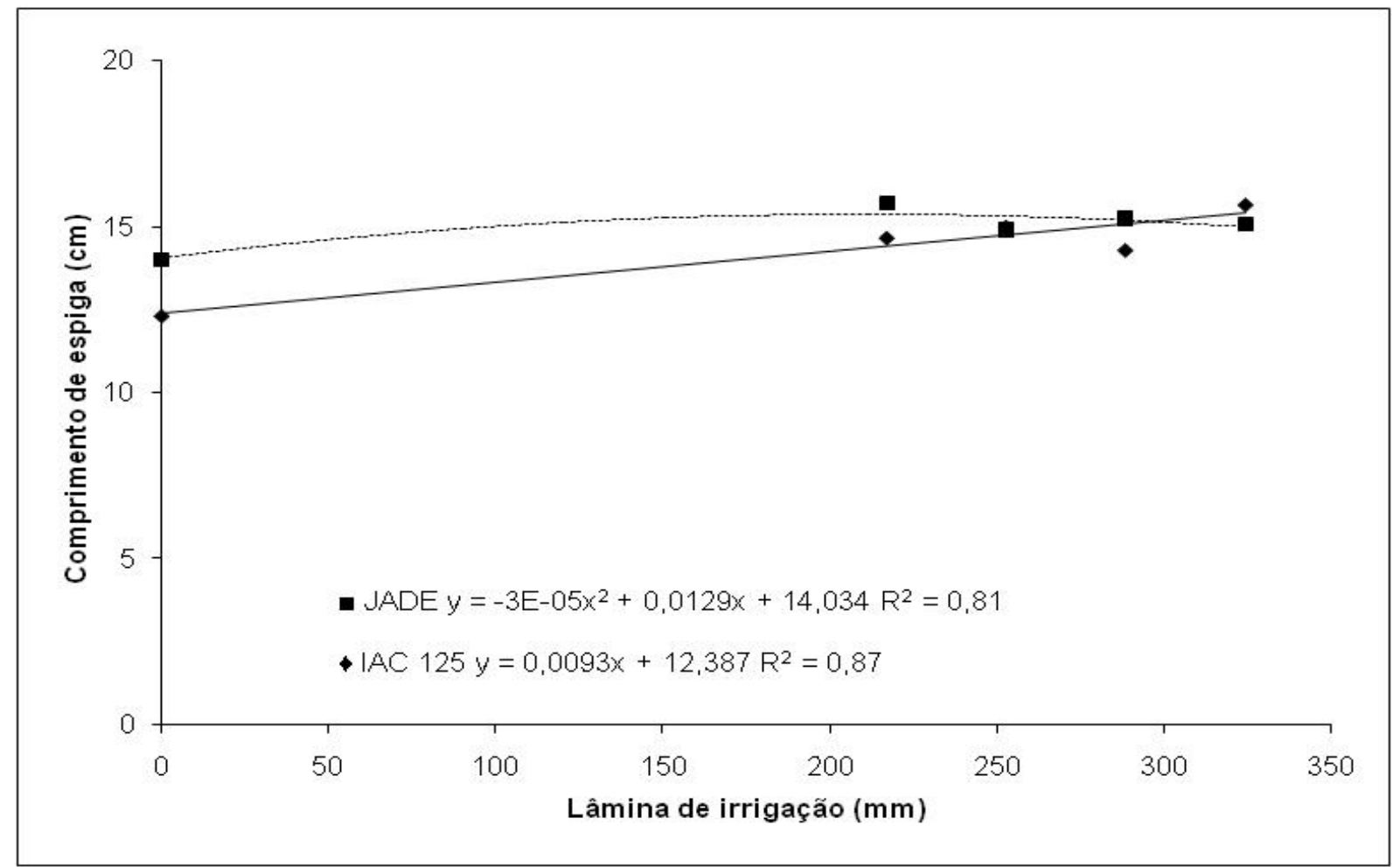

FIGURA 4 - Comportamento do comprimento de espiga para cada híbrido de milho pipoca em função da lâmina de irrigação. Umuarama, PR. Safra 2007/2008.

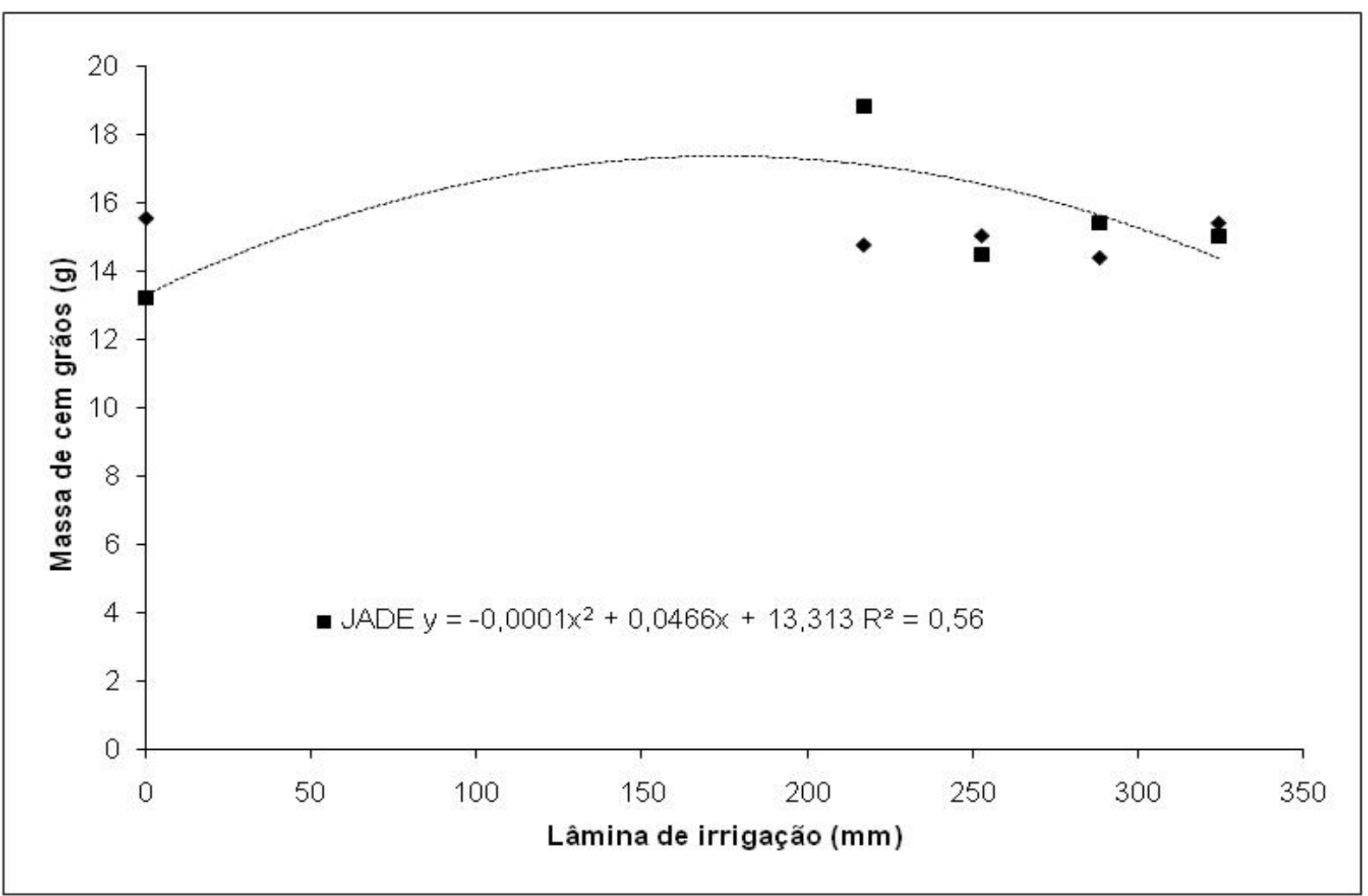

FIGURA 5 - Comportamento da massa de cem grãos para cada híbrido de milho pipoca em função da lâmina de irrigação. Umuarama, PR. Safra 2007/2008. 
Na Figura 6 o híbrido IAC 125 apresenta comportamento linear de produtividade em relação a lâmina de água aplicada. Já o Jade, comportamento quadrático assintótico, no qual o maior valor observado foi de $5.783,6 \mathrm{~kg} \mathrm{ha}^{-1}$, referente a lâmina $1,2 \mathrm{Kc}(288,5 \mathrm{~mm})$, lâmina esta $32,8 \mathrm{~mm}$ inferior a lâmina de referência.

A irrigação não interferiu na capacidade de expansão do híbrido Jade. Por outro lado, o híbrido IAC 125 respondeu de maneira linear, com incremento de $0,02 \mathrm{~mL} \mathrm{~g}^{-1}$ para cada $\mathrm{mm}$ de irrigação, Figura 7.

Por meio dos resultados é possível perceber diferenças de comportamento entre os genótipos em relação a demanda hídrica. De uma maneira geral, o híbrido Jade é menos exigente em água que o IAC 125, pois com exceção do componente altura de inserção da primeira espiga, onde se obteve ajuste linear, nos demais componentes os ajustes foram quadráticos. O comportamento linear do IAC 125 para a maior parte dos componentes analisados sugere manejo de irrigação com utilização de coeficientes de cultura superiores aos tomados como referência.

As respostas para a maior parte dos componentes analisados em relação a irrigação podem ser entendidas pelo balanço hídrico do período experimental (Figura 8). Apesar de ter ocorrido uma precipitação de $478,9 \mathrm{~mm}$, a distribuição das chuvas não foi homogênea, originando déficit hídrico no quarto, sétimo e do oitavo ao décimo segundo decêndio.

Por meio da Figura 8 pode-se perceber que foi necessário irrigar em todos os decêndios,
ÁVILA, M. R. et al. Híbridos de milho pipoca...

mesmo naqueles em que não se constataram déficits hídricos na escala decendial, indicando que mesmo dentro deste intervalo, a precipitação se deu por meio de poucos eventos.

Neste caso, observa-se que quando não há limitação de água durante o ciclo do milho pipoca há probabilidade de se alcançar elevadas produtividades em solo com baixo potencial de armazenamento de água, ou seja, solo de textura arenosa como o que foi utilizado para a condução deste trabalho. De acordo com Gomes et. al (2008) a ocorrência de curtos veranicos tem comprometido a produção de diversas culturas em solos arenosos devido à baixa capacidade de armazenamento hídrico.

Diante dos resultados obtidos no presente trabalho verificou-se que a irrigação, praticada de forma suplementar pode ser tornar uma opção de garantia de alta produtividade e boa qualidade de milho pipoca.

\section{CONCLUSÕES}

- A deficiência hídrica implica em resultados negativos ao desempenho da cultura do milho pipoca;

- Existe um comportamento diferenciado entre os híbridos avaliados em função das lâminas de irrigação

- O comportamento linear do IAC 125 para a maior parte dos componentes analisados sugere manejo de irrigação com utilização de coeficientes de cultura superiores aos tomados como referência para a cultura do milho.

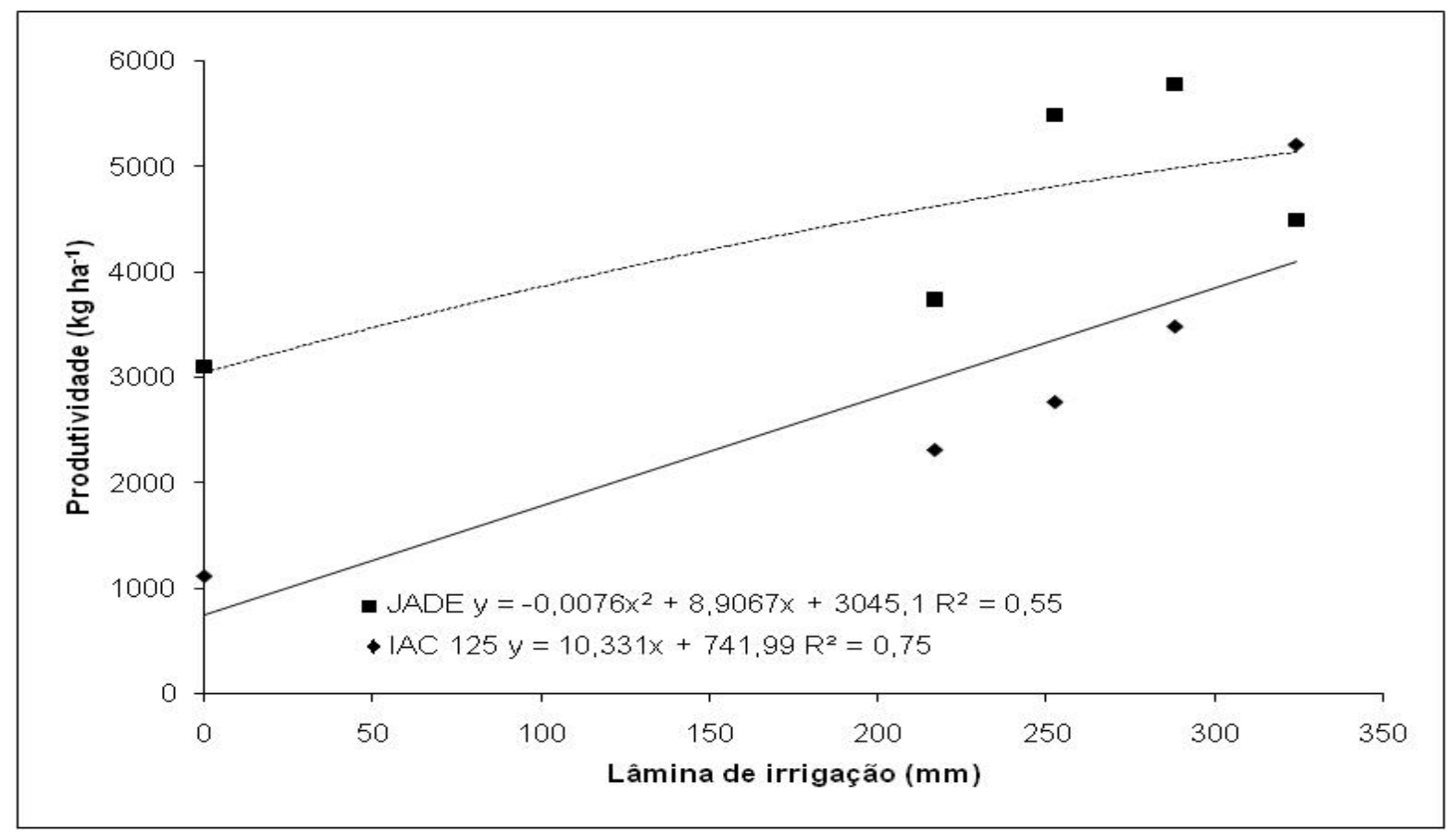

FIGURA 6 - Comportamento da produtividade para cada híbrido de milho pipoca em função da lâmina de irrigação. Umuarama, PR. Safra 2007/2008. 
ÁVILA, M. R. et al. Híbridos de milho pipoca...

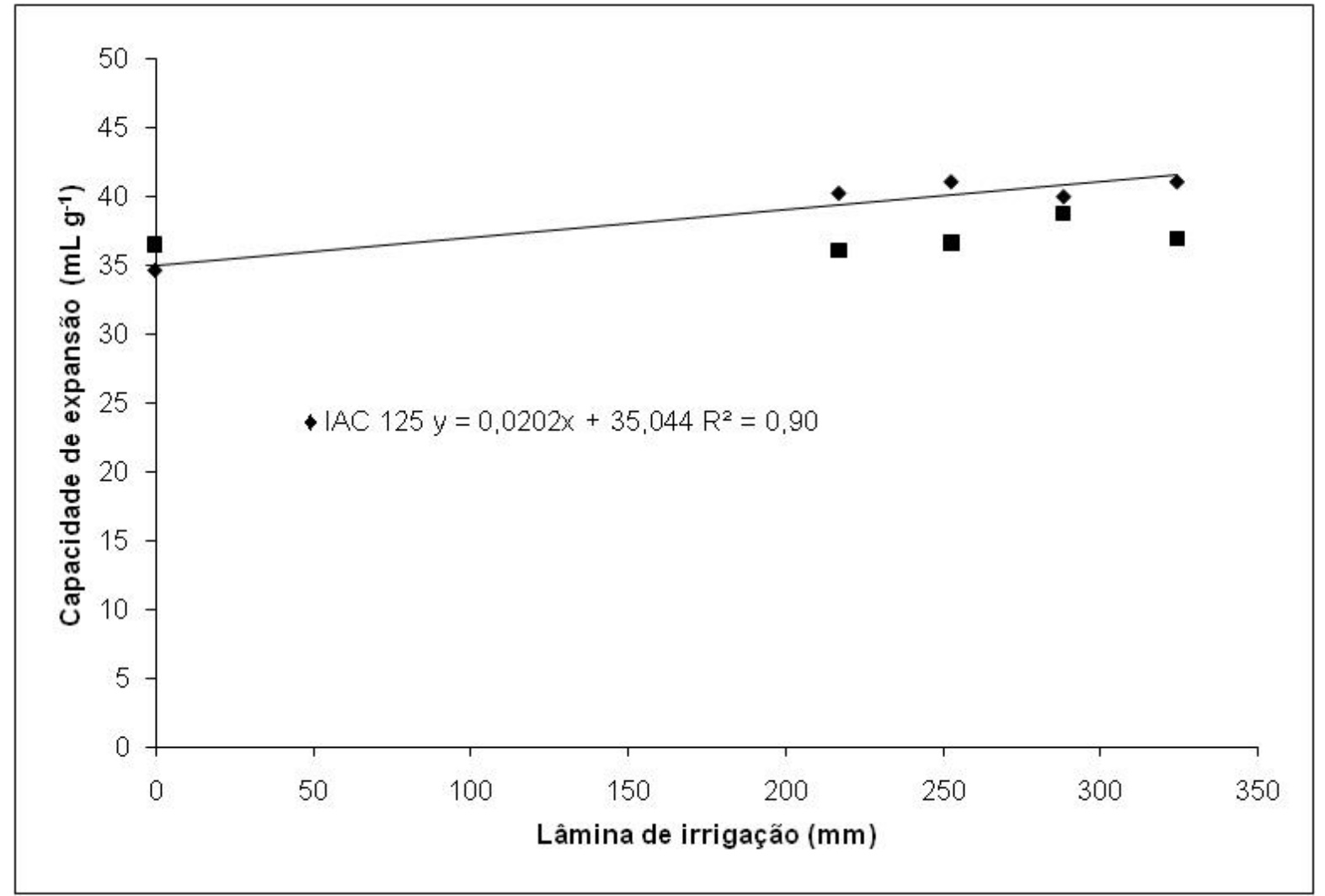

FIGURA 7 - Comportamento da capacidade de expansão para cada híbrido de milho pipoca em função da lâmina de irrigação. Umuarama, PR. Safra 2007/2008.

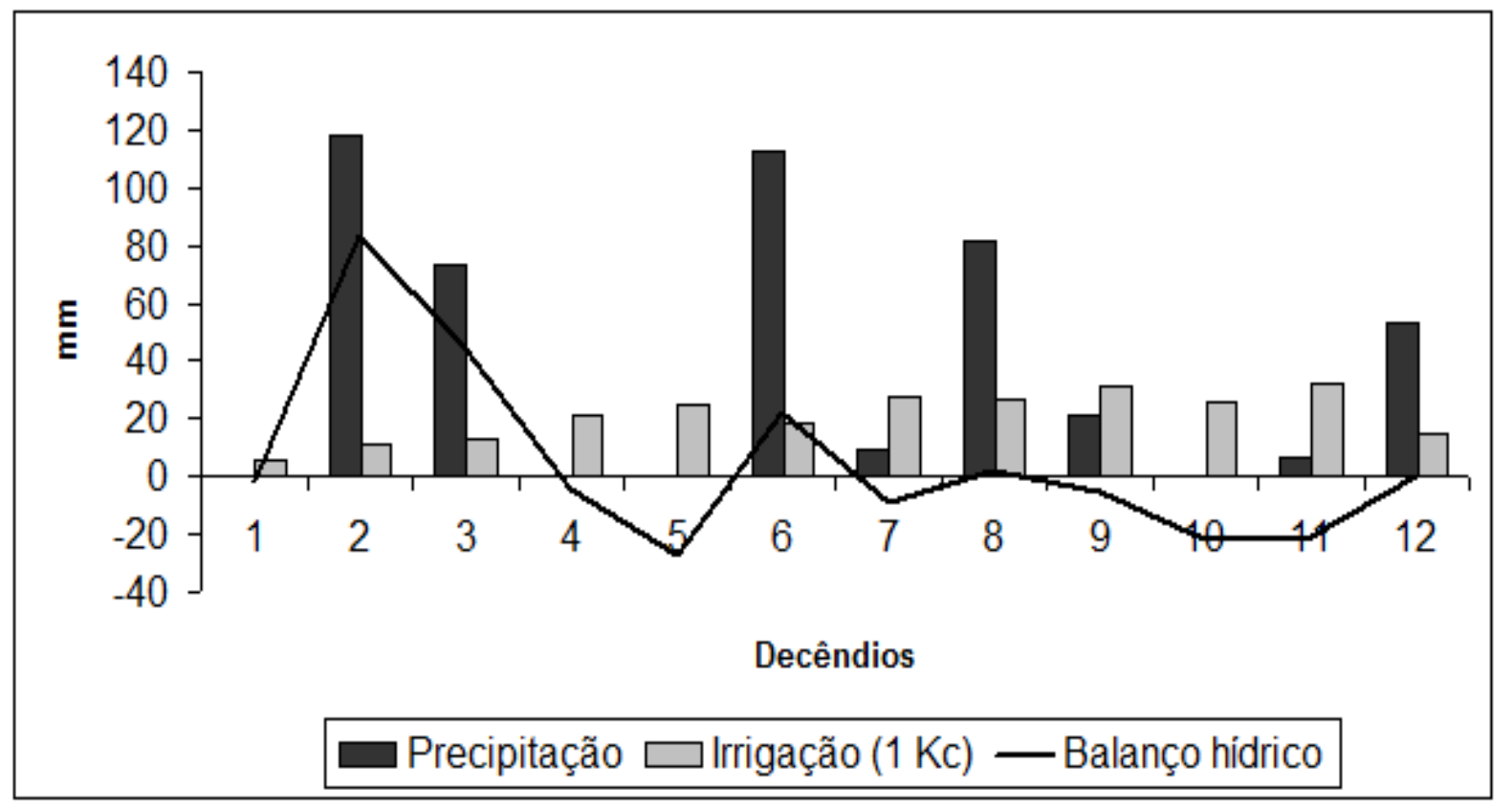

FIGURA 8 - Precipitação, irrigação e balanço hídrico durante o ciclo experimental. Umuarama, PR. Safra $2007 / 2008$. 
ÁVILA, M. R. et al. Híbridos de milho pipoca...

\section{REFERÊNCIAS}

1.ALFONSI, R.R. et al. Métodos agrometeorológicos para controle da irrigação. Campinas, Instituto Agronômico, 1990. 62p. (Boletim técnico, 133).

2.BERGAMASCHI, H. et al. Distribuição hídrica no período crítico do milho e produção de grãos. Pesquisa Agropecuária Brasileira, v. 39, n. 9, p. 831-839, 2004

3.CARDOSO, C. O. et al. Simulação do rendimento e riscos climáticos para o milho safrinha em Londrina - PR, utilizando o modelo CERES-Maize. Engenharia Agrícola, v.24, n.2, 291-300, 2004.

4.COIMBRA, R.R. Seleção entre famílias de meios-irmãos da população DFT 1-Ribeirão de Milho-pipoca. 2000, 54f Dissertação (Mestrado em Genética e Melhoramento de Plantas) - Universidade Federal de Viçosa, Viçosa, 2000.

5.CRUZ, C.D.; REGAZZI, A.J.; CARNEIRO, P.C.S. Modelos biométricos aplicados ao melhoramento genético. 3. ed. Viçosa: UFV, 2004. p. 50-101.

6.EMPRESA BRASILEIRA DE PESQUISA AGROPECUÁRIA - EMBRAPA. Sistema brasileiro de classificação dos solos. Brasília: EMBRAPA SOLOS, 1999. 412p.

7.FANCELLI, A.L.; DOURADO NETO, D. Produção de milho. 2 ed., Piracicaba: Livroceres, 2008. 360p.

8.GALVÃO, J.C.C. et al. Comportamento de híbridos de milho-pipoca em Coimbra, Minas Gerais. Ceres, v.47, n. 270, p. 201-218, 2000.

9.GOMES, E. P.; ÁVILA, M. R.; RICKLI, M. E.; PETRI, F. Water needs and yield of the sunflower crop under no-tillage and different supplementary irrigation depths in Arenito Caiuá, Paraná State. In: International Conference of Agricultural Engineering / XXXVII Brazilian Congress of Agricultural engineering, 2008, Igassu Falls. Anais do XXXVII Congresso Brasileiro de Engenharia Agrícola, Jaboticabal: SBEA, 2008 (CD ROM)

10.INSTITUTO AGRONOMICO DO PARANÁ - IAPAR. Cartas climáticas básicas do Estado do Paraná. Londrina: Instituto Agronômico do Paraná, 1987. 35p.

11.LOZADA, B.I.; ANGELOCCI, L.R. Efeito da temperatura do ar e da disponibilidade hídrica e na produtividade de um híbrido de milho. Revista Brasileira de Agrometeorologia, v. 7, n.1, p. 37-43, 1999.

12.MATZENAUER, R. Estimativa do consumo relativo de água para a cultura do milho no Estado do Rio Grande do Sul. Revista Brasileira de Agrometeorologia, v. 10, n. 1, p. 35-43, 2002.

13. OLIVEIRA, F.A. et al. Desenvolvimento inicial do milho-pipoca 'jade' irrigado com água de diferentes níveis de salinidade. Revista Verde, v.2, n.1, p.45-52, 2007.

14.PACHECO, C.A.P. et al. Estimativas de parâmetros genéticos nas populações CMS-42 e CMS-43 de milho pipoca. Pesquisa Agropecuária Brasileira, v.33, n.12, p.1995-2001, 1998.

15.PAIVA JUNIOR, M.C. et al. Desempenho de diferentes cultivares para milho verde em diferentes épocas e densidade de semeadura. Ciências Agrotecnológicas, v.25, n.5, p.1235-1247, 2001.

16.PEREIRA, A.R., ANGELOCCI, L.R., SENTELHAS, P.C. Agrometeorologia: fundamentos e aplicações práticas. In: PEREIRA, A.R., ANGELOCCI, L.R., SENTELHAS, P.C. Balanço hídrico de cultivos. Guaíba: Agropecuária, 2002. p. 269 - 288.

17.REZENDE, M.; ALBUQUERQUE, P.E.P.; COUTO, L. Manejo de Irrigação. In: RESENDE, M.; ALBUQUERQUE, P.E.P.; COUTO, L. (Eds.). A cultura do milho irrigado. Brasília: EMBRAPA, 2003, 317p.

18.ROLIM, G.S.; SENTELHAS, P.C. Balanço hídrico normal por Thornthwaite \& Mather (1955) V5.0. Piracicaba: Departamento de Física e Meteorologia, ESALQ-USP, 1999.

19.SAWAZAKI, E. A cultura do milho pipoca no Brasil. O Agronômico, v.53, n.2, p.11-13, 2001.

20.SAWAZAKI, E. et al. Influência do tamanho e umidade do grão na expansão da pipoca South American Mushroom. Bragantia, v. 45, n. 2, p. 363-370, 1986.

21.SAWAZAKI, E. Milho pipoca IAC 125. O Agronômico, v. 52, n. 2, p. 39, 2005.

22.SONG, A.; ECKHOFF, S.R. Optimum popping moisture content for popcorn kernels of different sizes. Cereal Chemistry, v.71, n.5, p.458-460, 1994.

Recebido em 19/02/2010 Aceito em 14/12/2011 